NASA/TM-2005-212966

\title{
Effect of Rolling Bearing Refurbishment and Restoration on Bearing Life and Reliability
}

Erwin V. Zaretsky

Glenn Research Center, Cleveland, Ohio

Emanuel V. Branzai

Bearing Inspection, Inc., Los Alamitos, California 
Since its founding, NASA has been dedicated to the advancement of aeronautics and space science. The NASA Scientific and Technical Information (STI) Program Office plays a key part in helping NASA maintain this important role.

The NASA STI Program Office is operated by Langley Research Center, the Lead Center for NASA's scientific and technical information. The NASA STI Program Office provides access to the NASA STI Database, the largest collection of aeronautical and space science STI in the world. The Program Office is also NASA's institutional mechanism for disseminating the results of its research and development activities. These results are published by NASA in the NASA STI Report Series, which includes the following report types:

- $\quad$ TECHNICAL PUBLICATION. Reports of completed research or a major significant phase of research that present the results of NASA programs and include extensive data or theoretical analysis. Includes compilations of significant scientific and technical data and information deemed to be of continuing reference value. NASA's counterpart of peerreviewed formal professional papers but has less stringent limitations on manuscript length and extent of graphic presentations.

- TECHNICAL MEMORANDUM. Scientific and technical findings that are preliminary or of specialized interest, e.g., quick release reports, working papers, and bibliographies that contain minimal annotation. Does not contain extensive analysis.

- CONTRACTOR REPORT. Scientific and technical findings by NASA-sponsored contractors and grantees.
- CONFERENCE PUBLICATION. Collected papers from scientific and technical conferences, symposia, seminars, or other meetings sponsored or cosponsored by NASA.

- SPECIAL PUBLICATION. Scientific, technical, or historical information from NASA programs, projects, and missions, often concerned with subjects having substantial public interest.

- TECHNICAL TRANSLATION. Englishlanguage translations of foreign scientific and technical material pertinent to NASA's mission.

Specialized services that complement the STI Program Office's diverse offerings include creating custom thesauri, building customized databases, organizing and publishing research results ... even providing videos.

For more information about the NASA STI Program Office, see the following:

- Access the NASA STI Program Home Page at http://www.sti.nasa.gov

- E-mail your question via the Internet to help@sti.nasa.gov

- Fax your question to the NASA Access Help Desk at 301-621-0134

- Telephone the NASA Access Help Desk at 301-621-0390

- Write to:

NASA Access Help Desk

NASA Center for AeroSpace Information 7121 Standard Drive

Hanover, MD 21076 
NASA/TM-2005-212966

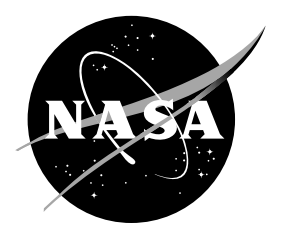

\section{Effect of Rolling Bearing Refurbishment and Restoration on Bearing Life and Reliability}

Erwin V. Zaretsky

Glenn Research Center, Cleveland, Ohio

Emanuel V. Branzai

Bearing Inspection, Inc., Los Alamitos, California

Prepared for the

2004 Annual Meeting and Exhibition

sponsored by the Society of Tribologists and Lubrication Engineers

Toronto, Canada, May 17-20, 2004

National Aeronautics and

Space Administration

Glenn Research Center 
Available from

NASA Center for Aerospace Information 7121 Standard Drive

Hanover, MD 21076
National Technical Information Service 5285 Port Royal Road Springfield, VA 22100

Available electronically at http://gltrs.grc.nasa.gov 


\title{
Effect of Rolling Bearing Refurbishment and Restoration on Bearing Life and Reliability
}

\author{
Erwin V. Zaretsky \\ National Aeronautics and Space Administration \\ Glenn Research Center \\ Cleveland, Ohio 44135 \\ Emanuel V. Branzai \\ Bearing Inspection, Inc. \\ Los Alamitos, California 90720
}

\begin{abstract}
For nearly four decades it has been a practice in commercial and military aircraft application that rollingelement bearings removed at maintenance or overhaul be reworked and returned to service. The work presented extends previously reported bearing life analysis to consider the depth $\left(\boldsymbol{Z}_{45}\right)$ to maximum shear stress $\left(\boldsymbol{\tau}_{45}\right)$ on stressed volume removal and the effect of replacing the rolling elements with a new set. A simple algebraic relationship was established to determine the $\boldsymbol{L}_{10}$ life of bearing races subject to bearing rework. Depending on the extent of rework and based upon theoretical analysis, representative life factors $(\boldsymbol{L F})$ for bearings subject to rework ranged from 0.87 to 0.99 the lives of new bearings. Based on bearing endurance data, 92 percent of the bearing sets that would be subject to rework would result in $\boldsymbol{L}_{10}$ lives equaling and/or exceeding that predicted for new bearings with the remaining 8 percent having the potential to achieve the analytically predicted life of new bearings when one of the rings is replaced at rework.. The potential savings from bearing rework varies from 53 to 82 percent that of new bearings depending on the cost, size and complexity of the bearing.
\end{abstract}

\section{Introduction}

Classical rolling-element fatigue, which is of subsurface origin, has been considered the prime life-limiting factor for rolling-element bearings. With proper design, handling, installation, lubrication, and system cleanliness, a rolling-element bearing will eventually fail by fatigue. Field experience has shown that less than 10 percent of the bearings removed from service have failed from end of life sub-surface fatigue. The remaining 90 percent of the failures are due to causes such as lubricant flow interruption, lubricant contamination, lubricant deterioration, excessive dirt ingestion, improper bearing installation, incorrect mounting fits, mishandling of bearings prior to installation, installing a contaminated bearing, manufacturing defects, ring growth in service, and corrosion. These other modes of failure are for the most part unpredictable. They tend to be of surface as opposed to subsurface originated. In general, failures due to surface defects occur much earlier than those failures due to classical rollingelement fatigue (refs. 1 to 3). As a result, in aircraft engine and drive train applications, a large number of bearings are discarded at overhaul or during periodic maintenance because of surface defects (ref. 4).

Typically, the total life of a commercial aircraft engine with repair can be expected to exceed $36000 \mathrm{hr}$. In general, new technology, first-run engines will get upward of $20000 \mathrm{hr}$ of operation before engine removal and refurbishment. Operating times for second-run engines after refurbishment are less than those of first run engines (ref. 5). Rolling-element bearing $\boldsymbol{L}_{5}$ life for these engines can range from 30000 to over $100000 \mathrm{hr}$. These bearings are usually designed for the anticipated life of the engine and are not dependent on the number of times the bearings are reworked. Usually, bearing failure by spalling is a cause for immediate engine removal. However, most damaged bearings are discovered because the engine was removed for other causes or were subject to the rework process.

For nearly four decades it has been a practice in commercial and military aircraft application that rollingelement bearings removed at maintenance or overhaul be reclaimed. Bearings are disassembled, cleaned, and visually inspected. If no major imperfections are found, the bearings are reassembled, lubricated, and packaged for further service. In some cases the rolling elements are replaced with new balls or rollers (ref. 6). 
When a raceway is damaged by fatigue spalling it is not repairable and the whole bearing may be rejected. However, if the mating race is not damaged, the damaged raceway may be replaced to render the bearing reusable and fit for its intended purpose, if allowed by applicable procedures.

Bearing refurbishment and bearing restoration, which are extensions of bearing reclamation entail honing (i.e., superfinishing) or grinding the raceways, and restoration of critical bearing surfaces to regain their original characteristics and dimensions as well as replacing the rolling elements with new ones (refs. 7 and 8). Honing restores the raceway finish to its original or improved condition and removes superficial surface defects (debrisdents, pits, scratched, corrosion, etc.) that would potentially reduce the bearing life. During refurbishment only 2.5 to $12.7 \mu \mathrm{m}$ ( 0.0001 to 0.0005 in) of parent raceway material is removed by honing. At each overhaul the rolling elements are replaced with a new set.

The process of bearing restoration by grinding was first reported in 1976 (refs. 7 to 9). If superficial but rejectable surface damage to the bearing raceways has been caused by dirt or debris, raceways can often be restored by grinding. In general, superficial damage extends less than $51 \mu \mathrm{m}$ (0.002 in.) from the surface. In 1985, Irwin, Anderson and Derner (ref. 10) developed a specification for bearing refurbishment and restoration (ref. 11).

In order to experimentally establish the reliability of the restoration process, a pilot program comprising 250 rolling-element bearings from three separate bearing types that had been removed from service at maintenance were subject to the bearing restoration process (ref. 8). Of this number, 30 bearings from each type were endurance tested for $1600 \mathrm{hr}$. No bearing failure occurred that was related to material removal from the raceways. Two bearings failed due to defective rolling elements, and these failures were typical of those that may occur in new bearings (refs. 4 and 8 ).

According to a theoretical equation derived by Coy, Zaretsky, and Cowgill (12) in 1977, the ratio of the $\boldsymbol{L}_{10}$ life of refurbished and restored bearings to the $\boldsymbol{L}_{\mathbf{1 0}}$ life of brand new bearings results in the life factors for bearings initially removed from service at their theoretical $\boldsymbol{L}_{10}$ and $\boldsymbol{L}_{50}$ lives, respectively. In general, the greater the amount of material removed in restoration, the closer is the approximation to the new bearing failure rate predicted by the theory. The theory also shows that if a given amount of material is to be removed in restoration, longer bearing life will be achieved with an earlier restoration time, say at the $\boldsymbol{L}_{10}$ life rather that the $\boldsymbol{L}_{50}$ life. The shortest life conditions occur when a minimum amount of stressed volume is removed at the $\boldsymbol{L}_{50}$ life.

There were a number of limitations to the theoretical work reported by Coy et al. (ref. 12). First, it was assumed that replacing the balls or rollers with new ones in a bearing did not change the resultant life of the bearing. Although this assumption is consistent with the Lundberg-Palmgren theory (ref. 13), according to Zaretsky's rule (ref. 14), this results in a lower life prediction value. Second, consistent with the Lundberg-Palmgren theory (ref. 13), the critical shearing stress was assumed to be the orthogonal shear stress, $\boldsymbol{\tau}_{\boldsymbol{o}}$. The maximum shear stress, $\boldsymbol{\tau}_{45}$ should be the critical shearing stress and its depth below the surface is the more appropriate value to be considered. Using the depth to $\boldsymbol{Z}_{\boldsymbol{o}}$ will result in higher prediction of life when considering bearing restoration. Third, it was assumed that the material removal at the inner and outer raceways as a fraction of their stressed volumes were the same for both raceways. This assumption is not necessarily consistent with the bearing restoration practice.

In view of the aforementioned, it is the objectives of the work reported herein to extend the work of Coy, et al. (ref. 12) to (a) include the depth to the maximum shear stress on stress volume removal, (b) determine the effect on bearing life by replacing rolling elements with a new set at rework, and (c) determine the effect of combinations of rework of the bearing components on resultant bearing life.

\section{Nomenclature}

$\begin{array}{ll}\boldsymbol{A} & \text { material-life factor } \\ \boldsymbol{a} & \text { semimajor axis of contact ellipse, m, (in.) } \\ \boldsymbol{b} & \text { semiminor axis of contact ellipse, m, (in.) } \\ \boldsymbol{C}_{\boldsymbol{D}} & \text { dynamic load capacity, N (lbf) } \\ \boldsymbol{c} & \text { stress-life exponent } \\ \boldsymbol{e} & \text { Weibull slope } \\ \boldsymbol{F} & \text { probability of failure, fraction or percent } \\ \boldsymbol{h} & \text { exponent } \\ \boldsymbol{L} & \text { life, number of stress cycles or hr } \\ \boldsymbol{L}_{\boldsymbol{1 0}} & \text { 10-percent life or life at which 90 percent of a population survives, number of stress cycles or hr } \\ \boldsymbol{L}_{\boldsymbol{5 0}} & \text { 50-percent life or life at which 50 percent of a population survives, number of stress cycles or hr }\end{array}$




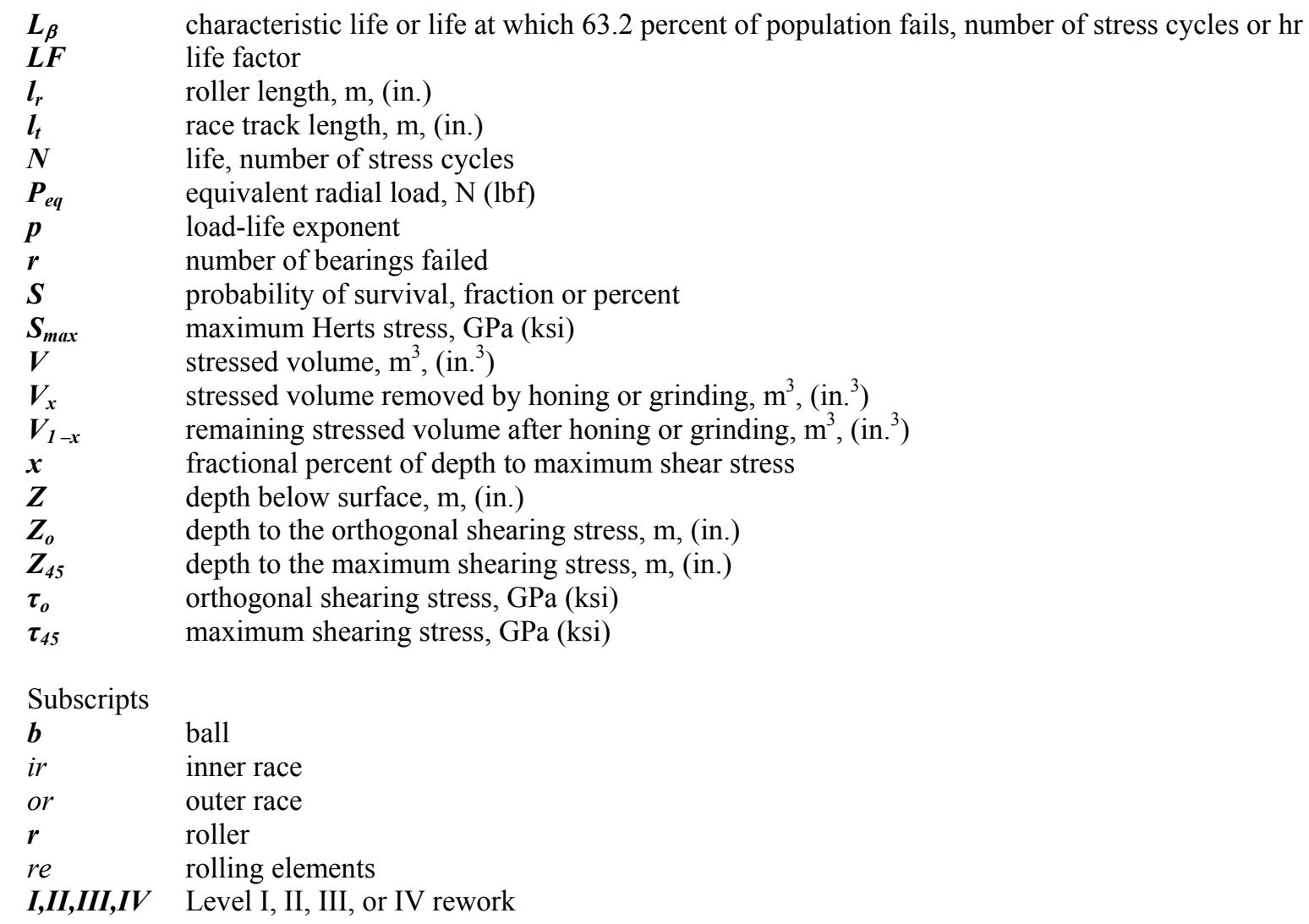

\section{Procedure}

\section{Bearing Rework}

In 1982 the U.S. Army Troop Support and Aviation Material Readiness Command (TSARCOM) in St. Louis, Missouri, requested that the NASA Lewis Research Center (now Glenn Research Center) organize a broad industry committee to improve both the reliability and availability of ball and cylindrical rolling-element bearings used in U.S. Army aircraft. A NASA, Army, Industry committee was formed that was comprised of 37 persons representing 25 companies and U.S. government organizations that included helicopter companies, bearing manufactures who supply bearings to the U.S. Army Aviation Command, and aircraft engine manufacturers (refs. 10 and 11).

To improve bearing availability (and aircraft readiness), the committee prepared a bearing restoration and refurbishment specification. Bearing restoration refers to regrinding used bearings to new bearing tolerances, including the replacement of the rolling elements. Bearing refurbishment refers to cleaning and inspecting bearings and fitting them with new rolling elements with the option to hone the bearing raceways. This bearing rework specification was based on previous work on bearing refurbishment and restoration performed by NASA Lewis Research Center (now Glenn Research Center) and the U.S. Army Research and Development Command (refs. 7 to 9). According to an early theoretical equation initially derived by Coy et al. (ref. 12) these bearings should achieve 70 to 100 percent of the lives of previously unrun bearings, depending on when the bearing was removed from initial service and the amount of material removed at restoration (ref. 4).

Bearing rework can be divided into four levels. These are (1) Reclamation, (2) Refurbishment, (3) Restoration by grinding, and (4) Remanufacture. The following procedures were recommended by the NASA, Army, Industry Committee (refs. 10 and 11) and updated by us.

Reclamation Level I.-Processing bearings involves inspecting a used bearing and checking/comparing it with new bearing drawing requirements. This process involves:

(a) Demagnetization. 
(b) Cleaning.

(c) Nondestructive testing, if applicable.

(d) Visual/microscopic inspection.

(e) Minor repair: buffing and polishing of inactive and active surfaces, stoning of nicks and gouges in corner radii

(f) Dimensional inspection.

(g) Reassembly (to include retainer riveting or snap-in retention).

(h) Dynamic testing (if required): rotation of bearing rings to permit evaluation of noise level, torque characteristics, and/or similar functional parameters.

(i) Lubrication/preservation.

(j) Packaging.

Refurbishment Level II.-Refurbishment of bearings is rework of bearings that goes beyond the scope of reclamation. This encompasses all of the operations of reclamation plus one or more of the following:

(a) Replacing rolling elements.

(b) Reworking/replacing retainers.

(c) Interchanging used components and/or substituting new components to create a different assembly identity.

(d) Grinding or polishing and/or plating of mounting surfaces as necessary to return to original drawing dimensions.

(e) Honing (superfinishing) raceways (not to exceed $12.7 \mu \mathrm{m}$ (0.0005 in.) total metal removal per surface).

Restoration Level III.- Restoration of bearings involves the removal of material by grinding operation. This term encompasses all of the operations of reclamation and refurbishment plus one or more of the following operations:

(a) Grinding races - up to $76 \mu \mathrm{m}(0.003$ in.) per surface.

(b) Installing oversize rolling elements.

(c) Installing original or replacement retainer when required.

Remanufacture Level IV. - Remanufacturing of bearings involves rework of bearings, where new components beyond the rolling elements and retainers are manufactured. This term encompasses all the operations of processing and may involve either refurbishing or regrinding of the old parts which are reused and one or more of the following:

(a) Manufacturing of a new ring.

(b) Manufacturing of a new retainer.

When a bearing raceway is damaged by fatigue spalling, it is not considered for rework. However, when there is superficial damage to the bearing raceways, caused by dirt or debris, raceways can often be restored by honing or grinding. In general, superficial damage extends to a depth less than $51 \mu \mathrm{m}(0.002 \mathrm{in}$.) from the surface.

For bearing refurbishment or restoration, repairable bearings are disassembled, the components are visually inspected, and the hardness of the bearing rings is measured. The components that are determined to be restorable are dimensionally inspected. Where necessary, the bearing faces, bores, and outer diameters are ground or polished and either nickel or chrome plated to a thickness that will allow the surfaces to be reground or polished to the original blueprint dimensions.

The bearing separator is stripped of its silver plating, where applicable, inspected for cracks, and replated. If it is required, the separator is replaced with a new one. The new rolling elements are placed within the separator and the bearing is reassembled.

During refurbishment both inner and outer raceways are honed to a depth of not more than $12.7 \mu \mathrm{m}(0.0005 \mathrm{in}$.), which removes all superficial damage and a small portion of the stressed material volume. The surface is finished to its original blueprint specification or better. The bearing is then refitted with new rolling elements having a diameter equal to the diameter of the elements previously contained in the bearing plus twice the depth of honing. The new rolling elements used are from the same nominal size family.

During restoration both inner and outer raceways are ground to a depth of not more than $76 \mu \mathrm{m}(0.003 \mathrm{in}$.), which removes all superficial damage and a portion of the stressed material volume. The surface is finished to its 
original blueprint specification or better. The bearing is then refitted with new rolling elements having a diameter equal to the diameter of the elements previously contained in the bearing plus twice the depth of regrinding. For the cylindrical roller bearings the roller length as well as the roller diameter is increased. The new rolling elements used usually exceed the original nominal size family. This large increase of the rolling elements may require the rework of the separator pockets or replacement of the cage.

\section{Bearing Life Analysis}

Lundberg-Palmgren Equation.-In probabilistic life models, the bearing physical characteristics, applied load, operating profile, and environment determine the probability of failure, assuming that the life is represented by a known probability function. W. Weibull (refs. 15 to 17) was the first to suggest a reasonable way to estimate material fracture strength with such a probability function. Based upon the work of Weibull (refs. 15 to 17), G. Lundberg and A. Palmgren (ref. 13) in 1947 showed that the probability of survival $\boldsymbol{S}$ could be expressed as a power function of the orthogonal shear stress $\tau_{o}$, life $N$, depth to the maximum orthogonal shear stress $\boldsymbol{Z}_{\boldsymbol{o}}$, and stressed volume $\boldsymbol{V}$. That is,

$$
\ln \frac{1}{\mathrm{~S}} \sim \tau_{o} \frac{N^{e}}{Z_{o}^{h}} V
$$

From equation (1),

$$
\boldsymbol{L}=\boldsymbol{N}=\boldsymbol{A}\left(\frac{1}{\tau_{\mathrm{o}}}\right)^{c / e}\left(\frac{1}{\boldsymbol{V}}\right)^{1 / e}\left[\boldsymbol{Z}_{\mathrm{o}}\right]^{h / e}
$$

where for ball bearings (fig. 1(a)),

$$
V=a l_{L} Z_{o}
$$

and for roller bearings (fig. 1(b)),

$$
V=l_{t} l_{L} Z_{o}
$$

Lundberg and Palmgren (ref. 13) incorporated into their analysis a method and distribution function for statistically describing the fatigue life of materials developed by Weibull (ref. 15) referred to as the two-parameter Weibull distribution function.

$$
\ln \ln \frac{1}{S}=\boldsymbol{e} \ln \left(\frac{\boldsymbol{L}}{\boldsymbol{L}_{\boldsymbol{\beta}}}\right) \text { where } \boldsymbol{0}<\boldsymbol{L}<\infty ; \quad 0<\boldsymbol{S}<1
$$

From equation (5), Lundberg and Palmgren (ref. 13) first derived the relationship between individual component life and system life. A bearing is a system of multiple components each with a different life. As a result, the life of the system is different from the life of an individual component in the system. The system life can be expressed, to a first order as

$$
\frac{1}{L_{10} \boldsymbol{e}}=\frac{1}{L_{10 i r} \boldsymbol{e}}+\frac{1}{L_{10 o r} \boldsymbol{e}}
$$

where the life of the rolling element by inference is incorporated into the life of each raceway. In properly designed and operated rolling-elements bearings fatigue of the cage or separator should not occur and, therefore, is not considered in determining bearing life and reliability. 

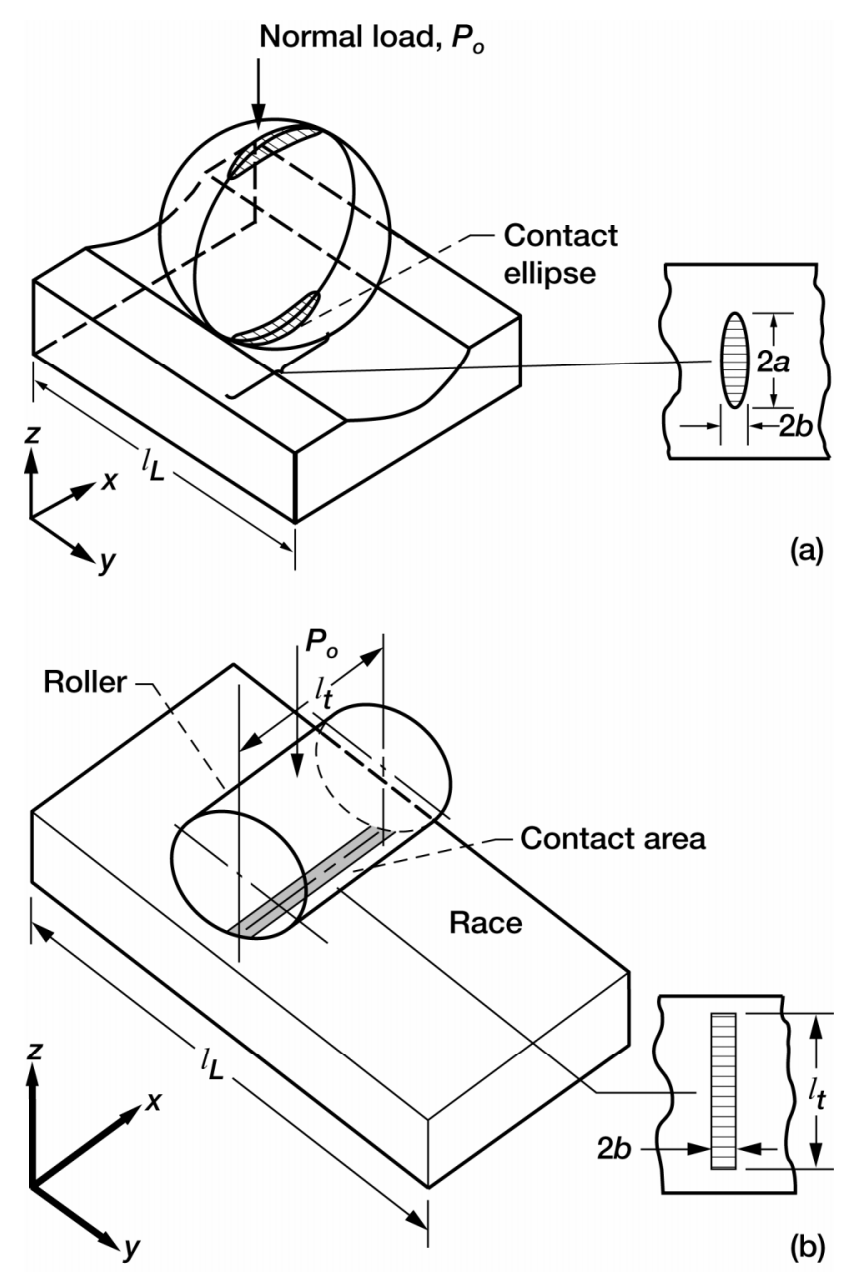

Figure 1.-Schematic of contact profile of rolling element on raceway. (a) Ball on raceway. (b) Roller on raceway.

From equations (1) and (6), Lundberg and Palmgren (ref. 13) derived the following relation:

$$
L_{10}=\left[\frac{C_{D}}{P_{e q}}\right]^{p}
$$

For equation (7), the load life exponent equals 3 for ball bearings and 4 for roller bearings. However, for roller bearings, Lundberg and Palmgren (ref. 18) choose to use $p$ equal 10/3.

Zaretsky Equation.-The work of E.V. Zaretsky (ref. 19) builds upon the work of Weibull (ref. 15) and Lundberg and Palmgren (ref. 13). Zaretsky eliminates the dependency of the stress-life relation on the Weibull slope $\boldsymbol{e}$. The depth to the critical shearing stress $\boldsymbol{Z}_{\boldsymbol{o}}$ is eliminated as a variable. He also uses the maximum shear stress $\tau_{45}$ instead of the orthogonal shear stress $\tau_{o}$ as the critical shearing stress. Equation (1) becomes

$$
\ln \frac{1}{S} \sim \tau_{45}^{c e} N^{e} V
$$

For ball bearings, the stressed volume is

$$
\boldsymbol{V}=\boldsymbol{a l}_{\boldsymbol{L}} \boldsymbol{Z}_{45}
$$


and for roller bearings,

$$
V=l_{t} l_{L} Z_{45}
$$

From equation (8), the life of the raceway is

$$
L=N=A\left(\frac{1}{\tau_{45}}\right)^{c}\left(\frac{1}{V}\right)^{1 / e}
$$

Using Zaretsky's rule (ref. 13), equation (6) should be written as follows:

$$
\left(1 / \boldsymbol{L}_{10}\right)^{e}=\left(1 / \boldsymbol{L}_{i r}\right)^{e}+\left(1 / \boldsymbol{L}_{\boldsymbol{r e}}\right)^{e}+\left(1 / \boldsymbol{L}_{\boldsymbol{o r}}\right)^{e}
$$

where the Weibull slope $\boldsymbol{e}$ is the same for each of the components as well as the bearing as system.

For radially loaded ball and roller bearings, the life of the rolling element set is equal to or greater than the life of the outer race. Let the life of the rolling element set (as a system) be equal to that of the outer race.

From equation (11)

$$
\left(1 / \boldsymbol{L}_{10}\right)^{e}=\left(1 / \boldsymbol{L}_{i r}\right)^{e}+2\left(1 / \boldsymbol{L}_{\boldsymbol{o r}}\right)^{e}
$$

where

$$
\boldsymbol{L}_{r e}=\boldsymbol{L}_{o r}
$$

For thrust loaded ball and roller bearings, the life of the rolling element set is equal to or greater than the life of the inner race but less than that of the outer race. Let the life of the rolling element set (as a system) be equal to that of the inner race.

From equation (11)

$$
\left(1 / \boldsymbol{L}_{10}\right)^{e}=2\left(1 / \boldsymbol{L}_{i r}\right)^{e}+\left(1 / \boldsymbol{L}_{o r}\right)^{e}
$$

where

$$
\boldsymbol{L}_{r e}=\boldsymbol{L}_{i r}
$$

Examples for using equations (11) to (13) are given in Zaretsky (ref. 14). As previously stated, the resulting values for $\boldsymbol{L}_{\boldsymbol{i} r}$ and $\boldsymbol{L}_{\boldsymbol{o r}}$ from these equations are not the same as those from equation (6). From the Zaretsky analysis, equation (7) remains unchanged. However, the values of the load life exponent $p$ becomes 4 and 5 for ball and roller bearings, respectively.

\section{Life of Reworked Bearings}

For most applications, bearing life is calculated based upon an $\boldsymbol{L}_{10}$ life or the time at which 90 percent of a population of bearings will exceed without failure and before which 10 percent of the population will have failed and have been removed from service. For most critical applications, most bearings will have been removed from service for various reasons on or before the $\boldsymbol{L}_{10}$ life. Experience has shown that generally not more than 3 percent of these bearings will manifest a rolling-element fatigue spall.

For purposes of analysis let us assume that we have 1000 each thrust-loaded, angular-contact ball bearings that have been run to their $\boldsymbol{L}_{10}$ of $10000 \mathrm{hr}$. Assume further that 10 percent of these bearings have been removed for reasons of rolling-element fatigue on or before reaching their $\boldsymbol{L}_{10}$ life. This leaves 900 out of the original 1000 bearings. Assume further that the remaining 900 bearings receive Level I rework and are put back into service. The $\boldsymbol{L}_{10}$ life of the reclaimed bearings is that time at which 90 additional bearings would be expected to fail or the 
time at which $190(100+90=190)$ total bearings have failed. This would be the $\boldsymbol{L}_{19}$ life of the original population. From equation (5), where

$$
\begin{gathered}
\boldsymbol{S}=(1-\boldsymbol{F})=(1-0.19)=0.81 \\
\boldsymbol{L}_{\boldsymbol{\beta}}=75940 \mathrm{hr} \text { and } \boldsymbol{e}=1.11 \\
\ln \ln \frac{1}{0.81}=1.11 \ln \left(\frac{\boldsymbol{L}_{19}}{75940}\right) \\
\boldsymbol{L}_{19}=18672 \mathrm{hr}
\end{gathered}
$$

Assume further, as an example, that the entire population of bearings are run to their $\boldsymbol{L}_{\mathbf{5} 0}$ life on or before which time 500 bearings are removed from service because of fatigue. The new $\boldsymbol{L}_{10}$ life would be based on failure of 50 of the remaining 500 bearings or the $\boldsymbol{L}_{55}$ life of the original population. From equation (5), the $\boldsymbol{L}_{\boldsymbol{5} 0}$ is

$$
\begin{aligned}
\ln \ln \frac{1}{0.5} & =1.11 \ln \left(\frac{\boldsymbol{L}_{50}}{75940}\right) \\
\boldsymbol{L}_{50} & =54592 \mathrm{hr}
\end{aligned}
$$

For $\boldsymbol{L}_{55}$,

$$
\begin{gathered}
\boldsymbol{S}=(1-0.55)=0.45 \\
\boldsymbol{L}_{55}=62014 \mathrm{hr}
\end{gathered}
$$

New $\boldsymbol{L}_{10}$ life $=62014-54592=7422 \mathrm{hr}$

$$
\text { Life Factor, } \boldsymbol{L F}_{\boldsymbol{I}}=7422 / 10000=0.742 \approx 0.74
$$

A new $\boldsymbol{L}_{10}$ life and life factor, $\boldsymbol{L F}$, can be calculated as illustrated above for removal at any time based upon Level I rework of the bearings. Level I life factors $(\boldsymbol{L F})$ for bearings removed at times to the $\boldsymbol{L}_{\boldsymbol{5} \boldsymbol{0}}$ life are given in table 1.

TABLE 1.-BEARING LIFE FACTOR, $\boldsymbol{L}_{\boldsymbol{I}}$, FOR LEVEL I REWORK AS FUNCTION OF BEARING REMOVAL TIME FROM SERVICE

\begin{tabular}{|l|c|c|c|c|c|c|c|}
\hline Time of removal & $\boldsymbol{L}_{5}$ & $\boldsymbol{L}_{10}$ & $\boldsymbol{L}_{15}$ & $\boldsymbol{L}_{20}$ & $\boldsymbol{L}_{30}$ & $\boldsymbol{L}_{40}$ & $\boldsymbol{L}_{50}$ \\
\hline Life factor, $\boldsymbol{L F}_{\boldsymbol{I}}$ & 0.88 & 0.87 & 0.84 & 0.82 & 0.79 & 0.76 & 0.74 \\
\hline
\end{tabular}

\section{Effect of Metal Removal}

Under Level II, III and IV rework for bearings, metal can be removed from the surface of one or both of the raceways. The effect of metal removal can increase the life of the raceway and increase the bearing life from that calculated for Level I rework.

Figure 2 is a sketch of the relative value of the maximum shearing stress $\tau_{45}$ as a function depth below the surface. The figure shows the effect of grinding or honing in redistributing the stress. In this figure $\boldsymbol{Z}_{45}$ is normalized to equal $1, \boldsymbol{x}$ is the depth of metal removal from honing or grinding. The normalized value of $\boldsymbol{x}$ is the fractional percent of metal removed. 


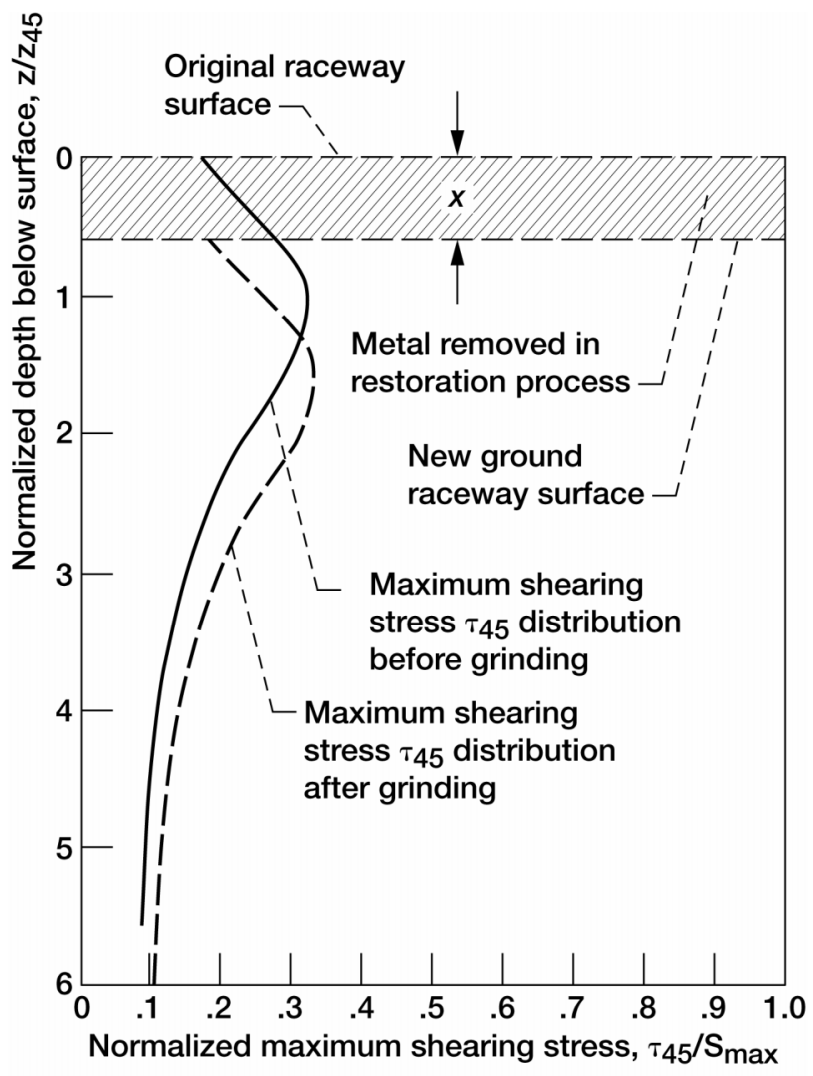

Figure 2.-Schematic of normalized maximum shearing stress $\tau_{45}$ as a function of normalized depth below raceway surface showing effect of metal removal in redistributing stress.

Referring to figure 2, it is assumed that the stress volume is only that material that is from the surface to the depth of the maximum value of the $\boldsymbol{\tau}_{45}$ shearing stress where $\boldsymbol{Z} / \boldsymbol{Z}_{45}=1$. It is further assumed that the metal at depths greater than $\boldsymbol{Z}_{45}$ are not stressed. Therefore, after material removal, metal having a stressed volume of

$$
V_{1-x}=a l_{L}(1-x) Z_{45}
$$

for ball bearings (fig. 1(a)), and

$$
V_{1-x}=l_{t} l_{L}(1-x) Z_{45}
$$

for roller bearings (fig. 1(b)) will have reduced life from that of an unrun raceway. Conversely, the stressed volume that is assumed not to have been subject to stress cycles after material removal is

$$
V_{x}=a l_{L} x Z_{45}
$$

for ball bearings (fig. 1(a)), and

$$
V_{x}=l_{t} l_{L} x Z_{45}
$$

for roller bearings (fig. 1(b)).

Each of the stressed volumes contributed to the life of the entire raceway having a stressed volume defined in equation (9). From equation (10) 


$$
L \sim\left(\frac{1}{V}\right)^{1 / e}
$$

The life of the entire volume from equation (26) can be further defined from the Lundberg-Palmgren equation, equation (6), where

$$
\frac{1}{L^{\boldsymbol{e}}}=\frac{1}{\boldsymbol{L}_{x}^{\boldsymbol{e}}}+\frac{1}{\boldsymbol{L}_{1-\boldsymbol{x}}^{\boldsymbol{e}}}
$$

From equation (26), where $\boldsymbol{V}_{\boldsymbol{x}}=\boldsymbol{x} \boldsymbol{V}$,

$$
\begin{gathered}
\frac{L_{x}}{L}=\left(\frac{V}{V_{x}}\right)^{1 / e}=\left(\frac{1}{x}\right)^{1 / e} \\
L_{x}=\left(\frac{1}{x}\right)^{1 / e} L
\end{gathered}
$$

and, where $\boldsymbol{V}_{1-x}=(1 /(1-x))^{1 / e}$,

$$
\begin{gathered}
\frac{\boldsymbol{L}_{1-x}}{\boldsymbol{L}}=\left(\frac{\boldsymbol{V}}{\boldsymbol{V}_{1-x}}\right)^{1 / \boldsymbol{e}}=\left(\frac{1}{1-\boldsymbol{x}}\right)^{1 / \boldsymbol{e}} \\
\boldsymbol{L}_{\boldsymbol{x}}=\left(\frac{1}{1-\boldsymbol{x}}\right)^{1 / \boldsymbol{e}} \boldsymbol{L}
\end{gathered}
$$

For the previous fractional stressed volume,

$$
\boldsymbol{L}_{1-\boldsymbol{x}}=\left(\boldsymbol{L F}_{\boldsymbol{I}}\right)\left(\frac{1}{1-\boldsymbol{x}}\right)^{1 / \boldsymbol{e}} \boldsymbol{L}
$$

For purpose of example, assume that a deep-groove ball bearing has $\boldsymbol{L}_{10}$ life of $10000 \mathrm{hr}$ and an outer-race life 4 times that of the inner-race. From equation (12),

$$
\begin{aligned}
& \boldsymbol{L}_{\boldsymbol{i r}}=13796 \mathrm{hr} \\
& \boldsymbol{L}_{\text {or }}=55183 \mathrm{hr} \\
& \boldsymbol{L}_{\boldsymbol{b}}=55183 \mathrm{hr}
\end{aligned}
$$

Further, assume that the bearing is removed from service undamaged at its $\boldsymbol{L}_{10}$ life of $10000 \mathrm{hr}$ and that the inner raceway is restored by grinding 20 percent of the stressed volume from its surface where $\boldsymbol{x}=0.20$.

From equations (5) and (30a), $10000 \mathrm{hr}$ operation of the inner raceway represents a value of probability of survival $S$ equal 0.927 for the inner raceway. Out of 1000 inner races in operation, 73 would be expected to have failed by $10000 \mathrm{hr}$.

Assuming that running time of the inner race is set back to zero, then a new race $\boldsymbol{L}_{10}$ life needs to be calculated in a similar manner to that previously discussed for the bearing represented by equations (14) to (17). For the inner raceway, the $\boldsymbol{L}_{10}$ life of the reclaimed raceway is that time at which 93 additional races would fail or where a total of $156(73+93=156)$ inner races have failed of the original population. This would be the $\boldsymbol{L}_{16}$ life of the original inner raceway population where

and, where

$$
\boldsymbol{S}=(1-\boldsymbol{F})=(1-0.16)=0.84
$$




$$
\boldsymbol{L}_{\boldsymbol{\beta}}=104767 \mathrm{hr} \text {. and } \boldsymbol{e}=1.11
$$

From equation (5),

$$
\boldsymbol{L}_{16}=21718 \mathrm{hr}
$$

From equations (30a) and (30b),

$$
\begin{gathered}
\text { New } \boldsymbol{L}_{10} \text { life }=\boldsymbol{L}_{16}-\boldsymbol{L}_{7}=21717-10000=11718 \mathrm{hr} \\
\quad \text { Life Factor } \boldsymbol{L F}_{\boldsymbol{I}}=11718 / 13796=0.849 \approx 0.85
\end{gathered}
$$

Recalculating the life of the Level III reground raceway, from equations (28) and (30a),

$$
\boldsymbol{L}_{\boldsymbol{x}}=\left(\frac{1}{0.2}\right)^{\frac{1}{1.11}}(13796)=58811
$$

From equations (29b), (30a), and (31d),

$$
\begin{aligned}
\boldsymbol{L}_{1-\boldsymbol{x}} & =(0.85)\left(\frac{1}{0.8}\right)^{\frac{1}{1.11}}(13796) \\
& =14337
\end{aligned}
$$

From equation (27), the life of the reground raceway is

$$
\begin{gathered}
\frac{1}{\boldsymbol{L}_{\text {ir }}^{1.11}}=\frac{1}{(58811)^{1.11}}+\frac{1}{(14337)^{1.11}} \\
\boldsymbol{L}_{\text {ir }}=12086 \mathrm{hr}
\end{gathered}
$$

From equations (32a) and (32c),

$$
\boldsymbol{L F}_{\text {III }}=12086 / 13796=0.876 \approx 0.88
$$

Plotting the life factors $\boldsymbol{L F}_{I I I}$ as a function of material removed from the raceway surface results in a linear relation between the resultant $\boldsymbol{L F}$ and the fractional material removed from the stressed volume where

$$
\boldsymbol{L} \boldsymbol{F}_{I I I}=\boldsymbol{L} \boldsymbol{F}_{I}+\boldsymbol{x}\left(1-\boldsymbol{L} \boldsymbol{F}_{I}\right)
$$

From the previous example where $\boldsymbol{x}=0.2$ and from equation (31d) where $\boldsymbol{L F}_{\boldsymbol{I}}=0.85$,

$$
\boldsymbol{L F}_{\text {III }}=0.85+0.20(1-0.85)=0.88
$$

Assume for purposes of example that the bearings are removed at their $\boldsymbol{L}_{50}$ life of $51709 \mathrm{hr}$. This corresponds to a survival $S=0.633$ for the inner race or at which time 37 percent of the inner races would be expected to fail. The new inner-race $\boldsymbol{L}_{10}$ life would be equivalent to failing an additional 63 inner races $(0.1 \times 663=63)$ for a total of 433 races $(370+63=433)$. From equation (5), the $\boldsymbol{L}_{43}$ life equals $62349 \mathrm{hr}$.

$$
\text { New } \boldsymbol{L}_{10} \text { life of race }=\boldsymbol{L}_{43}-\boldsymbol{L}_{\mathbf{3}}=62349-51709=10640 \mathrm{hr}
$$

From equations (30a) and (34a), the life factor is 


$$
\boldsymbol{L F}_{\boldsymbol{I}}=10640 / 13796=0.77
$$

Assuming a 20 percent stress volume removal $(\boldsymbol{x}=0.20)$, from equation (33a),

$$
\boldsymbol{L F}_{\text {III }}=0.77+0.20(1-0.77)=0.82
$$

The $\boldsymbol{L}_{10}$ life of the restored race from equations (30a) and (34c) is

$$
\text { New } \boldsymbol{L}_{10}=0.82(13796)=11312 \mathrm{hr}
$$

The same procedure as outlined above can be followed for the outer-race life and for those other times the bearings are removed from service.

\section{Results and Discussion}

\section{Effect of Rework on Bearing Life}

Bearing Reclamation Level I. - Life factors for Level I rework, where the bearing is returned to service after inspection only, are given in tables 1 and 2. Bearing removal at the $\boldsymbol{L}_{10}$ life results in a $\boldsymbol{L F}_{\boldsymbol{I}}$ of 0.867 . Removal of the bearing at the $\boldsymbol{L}_{50}$ life results in a $\boldsymbol{L} \boldsymbol{F}_{\boldsymbol{I}}$ of 0.742 . The life factor multiplied by the calculated bearing life from that obtained from the Lundberg-Palmgren equation (7) predicts the $\boldsymbol{L}_{10}$ life of the reclaimed bearing.

Based upon the work of Zaretsky, Poplawski, and Peters (refs. 20 to 22) and Vlcek, Hendricks and Zaretsky (ref. 23), it can be concluded that the life of these bearings are under-predicted. They suggest that for ball bearings the load-life exponent $\boldsymbol{p}$ from equation (7) should be 4 instead of 3 used by Lundberg and Palmgren (ref. 13). A load-life exponent of 4 best reflects the variation in the ratio of the actual life to the predicted life and $\boldsymbol{p}=3$ is conservative commensurate with good engineering practice (ref. 23).

Referring again to equation (7), the value for the load-life exponent $\boldsymbol{p}$ for cylindrical roller bearings as used by Lundberg and Palmgren is 10/3 or 3.333 (ref. 18). Poplawski, Peters and Zaretsky (refs. 21 and 22) stated that based upon their experience and analysis, the load-life exponent $\boldsymbol{p}$ of $10 / 3$ is incorrect and will underpredict roller bearing life. It was their recommendation that this value be revised to 4 with consideration given to increasing it to 5 . A load-life exponent of $\boldsymbol{p}=5$ best reflects the cylindrical roller bearing life results. However, by using a value of $\boldsymbol{p}=4$ a more conservative life prediction results that may be more commensurate with good engineering practice (ref. 23).

Table 3 shows the effect on bearing life factors of using different values of the load-life exponent $\boldsymbol{p}$ for ball and roller bearings at three load conditions. The table was normalized to $\boldsymbol{p}=4$ for ball bearings and $\boldsymbol{p}=5$ for roller bearings. What is apparent from this table and bearing data is that there is built into the Lundberg-Palmgren life calculations a very conservative safety or life factor depending on the load. For lightly loaded ball bearings, this factor could be as high as 20 and for heavily loaded ball bearings as much as 5 . For roller bearings, the factor for lightly loaded bearings is 148 and for heavily loaded bearings as much as 15 (ref. 23).

TABLE 3.-BEARING LIFE FACTOR, $\boldsymbol{L} \boldsymbol{F}$, BASED ON LOADLIFE EXPONENT, $\boldsymbol{p}$ (FROM REF. 23)

\begin{tabular}{|l|c|c|c|c|c|}
\hline \multirow{2}{*}{$\begin{array}{l}\text { Bearing load Peq, percent } \\
\text { dynamic load capacity, }\end{array} \boldsymbol{C}_{\boldsymbol{D}}$ (see eq. (2)) } & \multicolumn{5}{|c|}{ Load-life exponent, $\boldsymbol{p}$} \\
\cline { 2 - 7 } & Ball bearings & \multicolumn{3}{c|}{ Roller bearings } \\
\cline { 2 - 7 } & 3 & 4 & $10 / 3$ & 4 & 5 \\
\hline \multicolumn{5}{|c|}{ Life factor } \\
\hline Light load, 5 & ${ }^{\mathrm{a}} 20$ & 1 & ${ }^{\mathrm{b}} 148$ & 20 & 1 \\
\hline Normal load, 10 & 10 & 1 & 46 & 10 & 1 \\
\hline Heavy load, 20 & 5 & 1 & 15 & 5 & 1 \\
\hline${ }^{\mathrm{a}}$ Normalized to load-life exponent $\boldsymbol{p}=4$. \\
${ }^{\mathrm{b}}$ Normalized to load-life exponent $\boldsymbol{p}=5$.
\end{tabular}


The Lundberg-Palmgren equation is qualitatively correct but quantitatively conservative. All rolling-element bearing designs and life predictions are based in whole or in part on the Lundberg-Palmgren equations. Bearing data reported shows that 90 percent of bearings will have lives that exceed that predicted (ref. 23). Because of this, the removal rate for cause of Level I reclaimed bearings would not be expected to exceed that predicted for new bearings placed into service using the Lundberg-Palmgren equations.

The probability of survival for a new bearing at start-up is theoretically 100 percent $(\boldsymbol{S}=1)$ if infant mortality is ignored. However, for reworked bearings the probability of survival at start-up is less than 100 percent $(\boldsymbol{S}<1)$. This means that there is a finite probability of failure immediately on starting the reworked bearings. The physical reasons for this are simply that the material has already endured $N$ stress cycles and that some of the bearings may have already had subsurface incipient damage.

Refurbishment Level II. - Level II refurbishment encompasses all the work of Level I but includes replacing the rolling elements. It may also include removing metal from the raceways by honing (superfinishing). The honing process besides removing metal from the surface, removes any superficial damage to the race surfaces, and improves the surface finish of the raceway. As a result, bearings with incipient surface failures are restored for extended useful life.

Superficial damage to the raceway surface can act as stress risers that can substantially reduce the useful life of the bearing. However, this aspect of bearing refurbishment is somewhat hard to quantify. Therefore, the analysis is limited to addressing the effect of bearing rework on subsurface initiated fatigue life. It does not cover the benefits of removing harmful surface damage by honing that may occur as a result of bearing operation.

We again assume that the radially loaded ball bearing previously discussed is removed from service at the $\boldsymbol{L}_{10}$ life of $10000 \mathrm{hr}$. After inspection, new balls are placed in the bearing. From equation (31c)

$$
\boldsymbol{L}_{\text {ir }}=11718 \mathrm{hr}
$$

Calculating the new life of the outer raceway from equations (5) and (30b) at 10,000 $\mathrm{hr}$ is equivalent to 1.6 percent probability of failure for the outer race. This would mean that at $10000 \mathrm{hr}$, approximately 16 outer races $(0.016 \times 1000=16)$ out of 1000 would experience a failure. The remaining number of outer races would be $984(1000-16=984)$. The new $\boldsymbol{L}_{10}$ life for these races would be as follows:

$$
\text { New outer race } \boldsymbol{L}_{10} \text { life }=\boldsymbol{L}_{11}-\boldsymbol{L}_{1.6}=60428-10000=50428 \mathrm{hr}
$$

The Level I life factor for the outer race is

$$
\boldsymbol{L F}_{\boldsymbol{I}}=50428 / 55183=0.91
$$

Life of a new ball set from equation (30c),

$$
\boldsymbol{L}_{\boldsymbol{b}}=55183 \mathrm{hr}
$$

From equations (4), (35a), (35b) and (35d), the life of the refurbished bearing would be

$$
\begin{gathered}
\frac{1}{\boldsymbol{L}_{10}^{1.11}}=\frac{1}{(11718)^{1.11}}+\frac{1}{(50428)^{1.11}}+\frac{1}{(55183)^{1.11}} \\
\boldsymbol{L}_{\mathbf{1 0}}=8784 \mathrm{hr}
\end{gathered}
$$

The life factor for the Level II refurbished deep-groove bearing is

$$
\boldsymbol{L}_{\text {II }}=8784 / 10000=0.878 \approx 0.88
$$

From equation (16), the life of a Level I reclaimed bearing is $8,672 \mathrm{hr}$. The improvement in life by inserting new balls is approximately 1.3 percent.

If at Level II, the inner and outer races are honed removing 5 percent of the stressed volume where $\boldsymbol{x}=0.05$. From equations (31c) and (35a) the Level I life of the inner race is $11718 \mathrm{hr}$. The inner race Level I life factor is 


$$
\boldsymbol{L F}_{\boldsymbol{I}}=11718 / 13796=0.85
$$

From equation (33a), with surface removal by honing, the Level II inner race life factor is

$$
\boldsymbol{L F}_{\text {II }}=0.85+0.05(1-0.85)=0.86
$$

New inner-race life

$$
\boldsymbol{L}_{10}=0.86(13796)=11865 \mathrm{hr}
$$

From equation (35c), the outer race Level I life factor is

$$
\boldsymbol{L F}_{\boldsymbol{I}}=0.91
$$

From equations (33a) and (35c), the Level II outer-race life factor with honing is

$$
\boldsymbol{L F}_{\boldsymbol{I I}}=0.91+0.05(1-0.91)=0.91
$$

From equations (30b) and (37a), the resultant Level II outer-race life is

$$
\boldsymbol{L}_{10}=0.91(55183)=50428 \mathrm{hr}
$$

The life of the new ball set is obtained from equation (30c), where the $\boldsymbol{L}_{10}$ life of the ball set is $55183 \mathrm{hr}$. The life of the honed Level II deep-groove bearing from equation (4) is as follows:

$$
\begin{gathered}
\frac{1}{\boldsymbol{L}_{10}^{1.11}}=\frac{1}{(11865)^{1.11}}+\frac{1}{(50428)^{1.11}}+\frac{1}{(55183)^{1.11}} \\
\boldsymbol{L}_{\mathbf{1 0}}=8864 \mathrm{hr}
\end{gathered}
$$

The life factor for the honed Level II deep-groove bearing is

$$
\boldsymbol{L F}_{\text {II }}=8864 / 10000=0.886 \approx 0.89
$$

While honing the races at Level II refurbishment provides some additional reliability to the bearing by improving the surface finish of the races and the removal of superficial race defects, the resultant theoretical bearing life is only increased by 1 percent from that where only the ball set is replaced without honing. The same results would also be obtained with cylindrical roller bearings.

Repeating the above example for thrust-load angular-contact ball bearings, assume that the bearing has an $\boldsymbol{L}_{10}$ life of $10000 \mathrm{hr}$ and that the life of the outer race is 4 times that of the inner race, from equation (13), the life of the bearing components are as follows:

$$
\begin{aligned}
& \boldsymbol{L}_{i \boldsymbol{r}}=20468 \mathrm{hr} \\
& \boldsymbol{L}_{\text {or }}=81874 \mathrm{hr} \\
& \boldsymbol{L}_{\boldsymbol{b}}=20468 \mathrm{hr}
\end{aligned}
$$

If the bearings are removed at their $\boldsymbol{L}_{10}$ life of $10000 \mathrm{hr}$ and are subject to a Level II refurbishment with a new ball set and without honing, then the new lives of the components are calculated to be as follows:

$$
\begin{aligned}
& \boldsymbol{L}_{i \mathrm{r}}=18473 \mathrm{hr} \\
& \boldsymbol{L}_{\boldsymbol{o r}}=78878 \mathrm{hr}
\end{aligned}
$$




$$
\boldsymbol{L}_{\boldsymbol{b}}=20468 \mathrm{hr}
$$

From equation (11), the $\boldsymbol{L}_{10}$ life of the Level II refurbished angular-contact ball bearing is

$$
\begin{gathered}
\frac{1}{\boldsymbol{L}_{10}^{1.11}}=\frac{1}{(18473)^{1.11}}+\frac{1}{(78878)^{1.11}}+\frac{1}{(20468)^{1.11}} \\
\text { New } \boldsymbol{L}_{\boldsymbol{1 0}}=9500 \mathrm{hr}
\end{gathered}
$$

The life factor for the Level II angular-contact ball bearing is

$$
\boldsymbol{L F}_{\boldsymbol{I I}}=9500 / 10000=0.95
$$

From equation (16), the Level I life for this bearing is $8672 \mathrm{hr}$. The Level II restoration for the angular-contact ball bearing increased bearing life from Level I by 9.5 percent. The addition of the honing process applied to the inner and outer raceways will further increase the bearing Level II $\boldsymbol{L}_{\boldsymbol{1 0}}$ life. From equations (38a) and (39a) by Level I life factor for the inner race is

$$
\boldsymbol{L F}_{\boldsymbol{I}}=18473 / 20468=0.90
$$

Assume, as before, that 5 percent of the surface is removed by honing $(\boldsymbol{x}=0.05)$. Then, from equation (33a) the Level II life factor for the inner race becomes

$$
\boldsymbol{L F}_{\boldsymbol{I I}}=0.90+0.05(1-0.90) \approx 0.91
$$

The refurbished $\boldsymbol{L}_{10}$ life of the inner race is

$$
\text { New } \boldsymbol{L}_{10}=0.91(20468)=18628
$$

Repeating the above for the outer race, from equation (38b) and (39b),

$$
\boldsymbol{L F}_{\boldsymbol{I}}=78878 / 81874=0.963 \approx 0.96
$$

Again, assuming a 5 percent surface volume removal from the honing process, from equation (33a)

$$
\boldsymbol{L F}_{\boldsymbol{I I}}=0.96+0.05(1-0.96)=0.962 \approx 0.96
$$

The life factor and the life between Level I and Level II of the outer race remains virtually unchanged. From equation (11), the Level II $\boldsymbol{L}_{10}$ bearing life with honing becomes

$$
\begin{gathered}
\frac{1}{\boldsymbol{L}_{10}^{1.11}}=\frac{1}{(18626)^{1.11}}+\frac{1}{(78878)^{1.11}}+\frac{1}{(20468)^{1.11}} \\
\text { New } \boldsymbol{L}_{\mathbf{1 0}}=9538 \mathrm{hr}
\end{gathered}
$$

The bearing life with honing is only $38 \mathrm{hr}$ more than that without honing $(9538-9500=38)$. As before, the honing has a nominal effect on increasing bearing life as far as material stressed volume but can eliminate potential surface defects that can act as stress risers to decrease life.

Comparisons of life factors for Levels I and II rework are given in table 2. From the above discussion and the table, it can be reasonably concluded that Level II rework for radially loaded bearings such as deep-groove ball bearings and cylindrical roller bearings nominally increases bearing life over that obtained from Level I rework. However, for thrust loaded angular-contact ball bearings, Level II rework results in an approximate 10-percent increase in life from Level I rework and only a 5- percent reduction in life from that which is achievable with new bearings. 


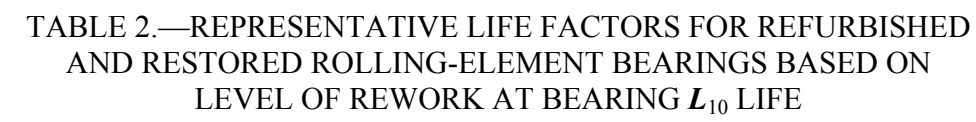

\begin{tabular}{|l|c|c|c|c|}
\hline \multirow{2}{*}{ Bearing type } & \multicolumn{4}{|c|}{ Life factor, $\boldsymbol{F}$} \\
\cline { 2 - 5 } & \multicolumn{4}{|c|}{ Rework level } \\
\cline { 2 - 5 } & I & II & III & IV \\
\hline Deep-groove ball & 0.87 & ${ }^{\mathrm{a}} 0.88-^{\mathrm{b}} 0.89$ & 0.90 & 0.99 \\
\hline Angular-contact ball & 0.87 & ${ }^{\mathrm{a}} 0.95-{ }^{\mathrm{b}} 0.96$ & 0.96 & $>0.99$ \\
\hline Cylindrical roller & 0.87 & ${ }^{\mathrm{a}} 0.88-^{\mathrm{b}} 0.89$ & 0.90 & 0.99 \\
\hline
\end{tabular}

${ }^{\mathrm{a}}$ Without honing

${ }^{\mathrm{b}}$ With honing

Restoration Level III. - Level III restoration encompasses all of the work of Levels I and II, but also includes removal by grinding of some or all of the stressed volume on both raceways. Assume again for example that the deep-groove ball bearing previously discussed is removed from service at its $\boldsymbol{L}_{10}$ life of $10000 \mathrm{hr}$. From equations (31c) and (35a), the Level I inner-race $\boldsymbol{L}_{10}$ life is

$$
\begin{gathered}
\boldsymbol{L}_{\boldsymbol{i r}}=11718 \mathrm{hr} \\
\boldsymbol{L F}_{\boldsymbol{I}}=0.85
\end{gathered}
$$

Assume for the inner raceway that 20 percent of the stressed volume is removed at Level III restoration $(\boldsymbol{x}=0.20)$, then from equations (33a) and (42b),

$$
\boldsymbol{L F}_{\text {III }}=0.85+0.20(1-0.85)=0.88
$$

From equations (30a) and (42c), the resultant Level III inner-race life is

$$
\boldsymbol{L}_{\boldsymbol{i r}}=0.88(13796)=12140 \mathrm{hr}
$$

For the outer race it is assumed that the stressed volume removed from the raceway at Level III restoration is 30 percent $(\boldsymbol{x}=0.30) .{ }^{1}$ From equations (30b) and (37c), Level I outer-race life is

$$
\boldsymbol{L}_{\text {or }}=50428 \mathrm{hr}
$$

and

$$
\boldsymbol{L F}_{\boldsymbol{I}}=0.91
$$

From equations (33a) and (43b), the outer-race life factor at the Level III restoration is

$$
\boldsymbol{L F}_{\text {III }}=0.91+0.3(1-0.91)=0.937 \approx 0.94
$$

And, from equations (30b) and (43c), the outer-race life is

$$
\boldsymbol{L}_{\text {or }}=0.94(55183)=51872 \mathrm{hr}
$$

At Level III restoration a new ball set is placed in the bearing. From equation (30c),

$$
\boldsymbol{L}_{\boldsymbol{b}}=55183 \mathrm{hr}
$$

${ }^{1}$ Because the Hertz stress is less on the outer raceway than on the inner raceway, the depth to the maximum shearing stress in the outer raceway is less than that in the inner raceway. For a given volume removed to the same depth in both the inner and outer raceways, a greater percent of the stressed volume is removed from the outer raceway. 
From equations (11), (42d), (43d) and (43e), the new $\boldsymbol{L}_{10}$ life at a Level III restoration is determined where

$$
\begin{gathered}
\frac{1}{\boldsymbol{L}_{10}^{1.11}}=\frac{1}{(12140)^{1.11}}+\frac{1}{(51872)^{1.11}}+\frac{1}{(55183)^{1.11}} \\
\text { New } \boldsymbol{L}_{\mathbf{1 0}}=9049 \mathrm{hr}
\end{gathered}
$$

The Level III deep-groove ball bearing life factor is

$$
\boldsymbol{L F}_{\text {III }}=9049 / 10000=0.905 \approx 0.90
$$

The above exercise is repeated for the angular-contact ball bearing previously discussed also having an $\boldsymbol{L}_{10}$ life of $10,000 \mathrm{hr}$. From equations (39a), the Level I inner race $\boldsymbol{L}_{10}$ life is

$$
\boldsymbol{L}_{\text {ir }}=18473 \mathrm{hr}
$$

And, from equations (38a) and (44a), the Level I life factor for the inner race is

$$
\boldsymbol{L F}_{\boldsymbol{I}}=18473 / 20468=0.90
$$

Assume a 20 percent surface volume removal by grinding $(\boldsymbol{x}=0.20)$, from equation (33a), the level III life factor is

$$
\boldsymbol{L F}_{\text {III }}=0.90+0.2(1-0.90)=0.92
$$

The Level III inner-race life for the angular-contact ball bearing is

$$
\boldsymbol{L}_{\boldsymbol{i r}}=0.92(20468)=18831 \mathrm{hr}
$$

For the outer race, assume that 30 percent of the stressed volume is removed. From equation (39b), the Level I outer-race $\boldsymbol{L}_{10}$ life is

$$
\boldsymbol{L}_{\boldsymbol{o r}}=78878 \mathrm{hr}
$$

and, from equations (38b) and (45a), the Level I life factor is

$$
\boldsymbol{L F}_{\boldsymbol{I}}=78878 / 81874=0.96
$$

Then, from equation (33a), the Level III outer-race life factor is

$$
\boldsymbol{L F}_{\text {III }}=0.96+0.3(1-0.96)=0.97
$$

The Level III outer-race $\boldsymbol{L}_{10}$ life is

$$
\boldsymbol{L}_{\boldsymbol{o r}}=0.97(81874)=79418 \mathrm{hr}
$$

The new ball set life from equation $(38 \mathrm{c})$ is

$$
\boldsymbol{L}_{\boldsymbol{b}}=20468 \mathrm{hr}
$$

From equations (11), (44d), (45d) and (45e), the Level III $\boldsymbol{L}_{10}$ life of the angular-contact ball bearing is

$$
\frac{1}{\boldsymbol{L}_{10}^{1.11}}=\frac{1}{(18831)^{1.11}}+\frac{1}{(79418)^{1.11}}+\frac{1}{(20468)^{1.11}}
$$




$$
\text { New } \boldsymbol{L}_{10} \text { life }=9594 \mathrm{hr}
$$

The resultant Level III life factor for the angular-contact ball bearing is

$$
\boldsymbol{L F}_{\boldsymbol{I I I}}=9594 / 10000=0.959=0.96
$$

Remanufacturing Level IV. - Level IV bearing remanufacturing usually comprises replacing one of the rings with a new component. In some applications, the outer ring of the bearing is also a structural member of a turbine engine (usually a flanged outer ring). It is therefore cost effective to keep the outer ring and only replace the inner ring and the rolling elements. However, for cylindrical roller bearings where there is an inner-ring riding cage/rolling-element assembly it is cost effective to keep the inner ring and separator and replace the outer ring and the rollers.

Assume that the inner ring of the deep-groove bearing is replaced along with the ball set. The Level IV $\boldsymbol{L}_{10}$ life for the deep-groove ball bearing from equations (11), (30a), (30c) and (43d) is

$$
\begin{gathered}
\frac{1}{\boldsymbol{L}_{10}^{1.11}}=\frac{1}{(13796)^{1.11}}+\frac{1}{(51872)^{1.11}}+\frac{1}{(55183)^{1.11}} \\
\boldsymbol{L}_{\mathbf{1 0}}=9905 \mathrm{hr}
\end{gathered}
$$

The Level IV life factor is

$$
\boldsymbol{L F}_{\boldsymbol{I V}}=9905 / 10000=0.99
$$

The Level IV life of the angular-contact ball bearing from equations (11), (38a), (38c) and (45d) is

$$
\begin{gathered}
\frac{1}{\boldsymbol{L}_{10}^{1.11}}=\frac{1}{(20468)^{1.11}}+\frac{1}{(79418)^{1.11}}+\frac{1}{(20468)^{1.11}} \\
\boldsymbol{L}_{10}=9970
\end{gathered}
$$

The Level IV life factor is

$$
\boldsymbol{L F}_{\boldsymbol{I}}=9970 / 10000=0.997 \approx>0.99
$$

Assume for purposes of example that a cylindrical roller bearing having an inner ring riding separator (cage) is removed at its predicted $\boldsymbol{L}_{10}$ life of $10000 \mathrm{hr}$. and is subject to Level IV restoration. The inner raceway is honed whereby 5 percent of the surface material is removed. The outer race and roller set are replaced with new ones. If the life or the outer race is 4 times that of the inner race, then the $\boldsymbol{L}_{\mathbf{1 0}}$ lives of the inner race, outer race and roller set are 13796,55183 and 55 183, respectively. The life factor for the inner race after honing is calculated from table 1 and equation (33a) where

$$
\boldsymbol{L F}_{\boldsymbol{i r}}=0.87+0.05(1-0.87) \approx 0.88
$$

The life of the restored inner race is $12140 \mathrm{hr} .(0.88 \times 13796=12140)$ and the calculated life of the restored bearing is $9127 \mathrm{hr}$. The Level IV life factor $\left(\boldsymbol{L} \boldsymbol{F}_{\boldsymbol{I}}\right)$ for this bearing is $0.91(9127 / 10000 \approx 0.91)$. Where the inner race is reground removing 20 percent of the material from the raceway, the resultant Level IV life factor $\left(\boldsymbol{L} \boldsymbol{F}_{\boldsymbol{I V}}\right)$ is increased from 0.91 to 0.92 or approximately 1 percent. However, the resultant increase in cost from grinding additional material from the raceway may not be justified by the small increase in calculated life for this example.

From the above analysis, Level IV restoration has the potential to restore the life and reliability of bearings removed from service to nearly that of new bearings. 


\section{Comparison with Bearing Endurance Data}

Representative life factors $(\boldsymbol{L F})$ for the various levels of bearing refurbishment and restoration are summarized in table 2. These life factors vary from 0.87 to $>0.99$ depending on the amount of rework that the bearings are subjected to and assuming that they are removed from service on or before their $\boldsymbol{L}_{10}$ life. The application of these life factors to actual bearing data needs to be examined.

Harris (refs. 24 and 25) analyzed endurance data from 62 rolling-element bearing sets. A discussion of the Harris data can be found in references 20 and 21. These data were obtained from four bearing manufacturers. Two helicopter manufacturers, three aircraft engine manufacturers, and U.S. Government agency-sponsored technical reports. The data sets comprised of deep-groove radial ball bearings, angular-contact ball bearings, and cylindrical roller bearings for a total of 7935 bearings. Of these, 5321 bearings comprised one sample size for a single cylindrical roller bearing leaving 2614 bearings distributed among the remaining bearing types and sizes. Among the 62 rolling-element bearing endurance sets, 11 had one or no failure and could not be used for analysis (ref. 23).

These data are plotted in figure 3 using the number of bearings failed rather than the number of bearings in a set. A summary of the Harris data is contained in reference 23.

Vlcek, Hendricks and Zaretsky (ref. 23) established a simple algebraic relation for the upper and lower $\boldsymbol{L}_{10}$ life limits as a function of the number of bearings failed for any geometry. These limits are also plotted in figure 3.

Relating these results to bearing rework, the appropriate life factor from table 2 is applied to the actual of true lives obtained (fig. 3). The resultant $\boldsymbol{L}_{10}$ life should fall between the maximum and minimum values if the rework life is no different from that analytically predicted (calculated) life using the Lundberg-Palmgren equations. If, however, the $\boldsymbol{L}_{10}$ life is greater than the Maximum Variation $\boldsymbol{L}_{10}$ Life, then the true life is probably greater than that calculated. If the $\boldsymbol{L}_{10}$ life is less than the Minimum Variation $\boldsymbol{L}_{10}$ Life, it must be reasonably concluded that the true $\boldsymbol{L}_{10}$ life is probably less than that calculated for new unused bearings.

Using the above criteria, of the 51 sets of bearing data summarized in figure 3,47 sets of bearings, if subject to Levels I to III rework, would result in lives that would statistically be no different than that of new bearings. The 4 sets of deep-groove bearings that border on the minimum variation life may not be suitable for Levels I to III rework. However, they can be subject to Level IV rework to bring them into an acceptable range.

Based upon the above discussion, it may be reasonably concluded that 92 percent of the bearing sets will provide $\boldsymbol{L}_{10}$ lives equal to or greater than that calculated for new bearings when subject to Levels I through III rework. Further, 100 percent of the $\boldsymbol{L}_{10}$ lives of all bearing sets will provide lives no different from variations in $\boldsymbol{L}_{10}$ life from the analytically predicted (calculated) life of new bearings when subject to Level IV rework.

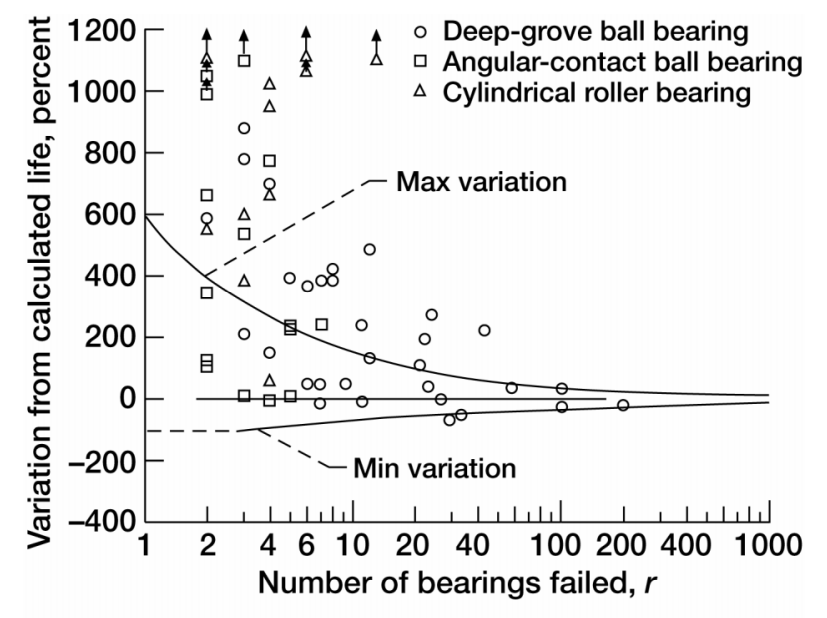

\footnotetext{
Figure 3.-Variation between actual and calculated $L_{10}$ bearing lives for 51 sets of deep-groove and angular-contact ball bearings and cylindrical roller bearings from Harris (24) and Harris and $\mathrm{McCool}$ (25). (from Vlcek, et al. (23)).
} 


\section{Cost-Benefit Analysis}

Aircraft and terrestrial gas turbine engines contain up to 7 main bearings. It is estimated that about 30 percent of the total engine bearings become suspect during maintenance checks and are candidates for rework. H. Hanau (ref. 7) in 1976 was first to discuss the economics and cost benefits of bearing rework. At that time, based upon statistics from the U.S. Army Aeronautical Depot Maintenance Center in Corpus Christi, Texas; Hanau (ref. 7) concluded that a 90 percent yield can be achieved by the restoration process. This restoration process would only include Levels III and IV and be beyond those bearings that would be reclaimed at Level I or restored at Level II. He estimated the cost to restore rolling-element bearings by grinding (Levels III and IV) ranged from 27 to 47 percent of new bearing cost depending on bearing size and complexity. The potential cost saving varied from 53 to 73 percent the cost of a new bearing. The more complex a bearing is, the greater the savings achieved by Levels III and IV restoration.

Hanau (ref. 7) also presented data showing the potential amount of steel and critical alloying savings for UH-1 helicopter engine and transmission bearings based on bearing rework. These data are shown in table 4 .

TABLE 4.-CRITICAL ALLOYING ELEMENT SAVINGS FOR UH-1 HELICOPTER ENGINE AND DRIVE TRAIN BEARINGS (FROM REF. 7)

\begin{tabular}{|l|c|c|c|c|c|c|}
\hline \multirow{2}{*}{$\begin{array}{c}\text { Material recycled } \\
\text { through bearing } \\
\text { rework }\end{array}$} & \multirow{2}{*}{$\begin{array}{c}\text { Total raw } \\
\text { material savings, } \\
\mathrm{kg} / \mathrm{yr}(\mathrm{lbs} / \mathrm{yr})\end{array}$} & \multicolumn{5}{|c|}{ Alloying element, kg/yr (lbs/yr) } \\
\cline { 5 - 8 } & $23224(51200)$ & $1103(2432)$ & -------- & $1045(2304)$ & -------- & $302(666)$ \\
\hline AISI M-50 & $7983(17600)$ & ------------- & $32(70)$ & $122(270)$ & $32(70)$ & --------- \\
\hline AISI 52100 & $31208(68800)$ & $1103(2432)$ & $32(70)$ & $1168(2574)$ & $32(70)$ & $302(666)$ \\
\hline Total $\mathrm{kg} / \mathrm{yr}(\mathrm{lbs} / \mathrm{yr})$ & & &
\end{tabular}

For ground based power applications, the main bearings for the GG4 engine costs approximately $\$ 121,000$ if purchased new. For Level I and II reclamation and refurbishment, the cost is $\$ 15,000$. For the LM2500 engine, new bearings cost $\$ 40,469$. The cost of Level I and II rework is $\$ 20,130$. The respective savings are 88 and 50 percent the cost of new bearings. The turn time for Level I and II rework is 3 and 14 days, respectively.

For aircraft gas turbine engines, the CFM56 engine uses 5 main bearings and approximately 26 accessory bearings all of which are candidates for Level II refurbishment. The cost of new main bearings is $\$ 80,000$. Four of the 5 main bearings can be refurbished. The fifth bearing needs to be purchased. The total cost to refurbish the 4 bearings and to purchase a new bearing is $\$ 25,000$ or a savings of 69 percent. The Level II rework costs for other aircraft engines is shown in figure 4. These data show potential savings ranging from 71 to 82 percent of new bearing costs depending on the cost, size and complexity of the bearing.

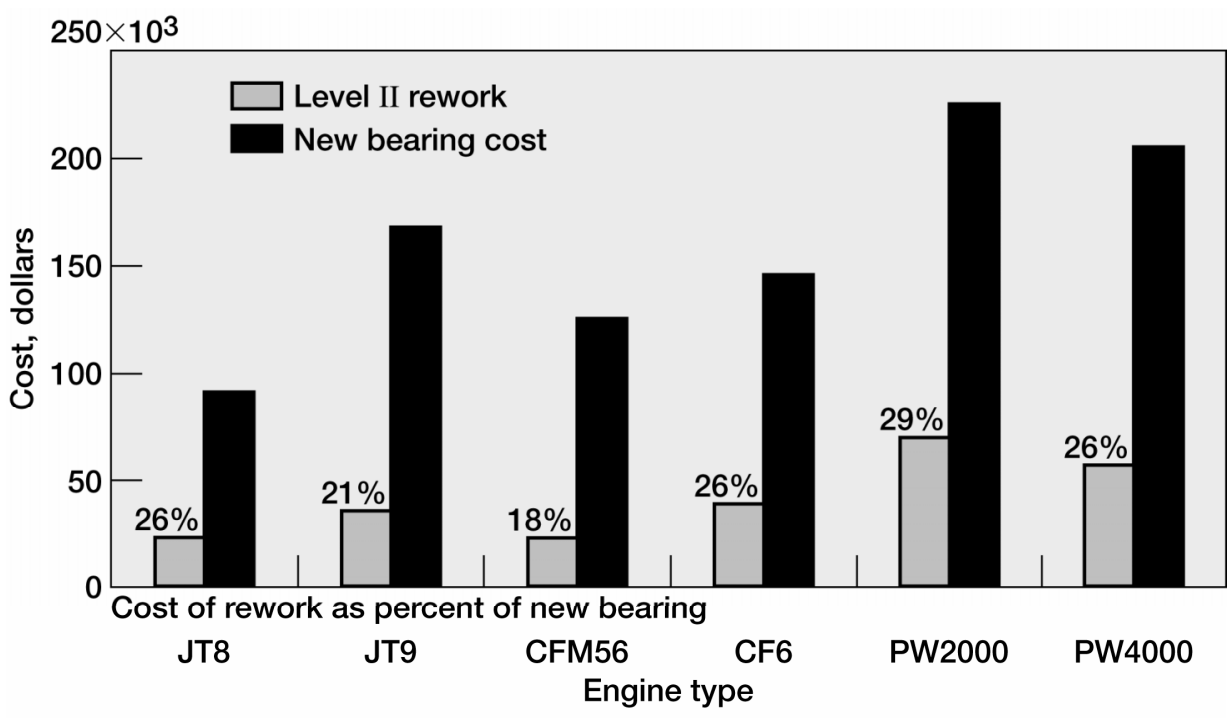

Figure 4.-Comparative costs of Level II rework and new bearings for six aircraft gas turbine engines. 


\section{Summary of Results}

For nearly four decades it has been a practice in commercial and military aircraft applications that rollingelement bearings removed at maintenance or overhaul be refurbished or restored and returned to service. The work reported herein extended the previously reported bearing life analysis of these reworked bearings to consider the depth $\left(\boldsymbol{Z}_{45}\right)$ to maximum shear stress $\left(\boldsymbol{\tau}_{45}\right)$ on stress volume removal and the effect of replacing the rolling elements with a new set at bearing rework. The effect of combinations of rework of the bearing components and/or their replacements on resultant bearing life was evaluated. The analysis was applied to endurance data for 51 sets of bearings. A cost benefit analysis was performed. The following results were obtained:

1. A simple algebraic relationship was established to determine the $\boldsymbol{L}_{10}$ life of bearing races subject to partial removal of its stressed volume as a function of the depth $\left(\boldsymbol{Z}_{45}\right)$ to the maximum shear stress $\left(\boldsymbol{\tau}_{45}\right)$ at refurbishment or restoration.

2. Depending on the extent of rework and based upon theoretical analysis, representative life factors $(\boldsymbol{L F})$ for bearings subject to refurbishment and restoration ranged from 0.87 to 0.99 the lives of new bearings where the bearings are removed from service (before rework) on or before their predicted $\boldsymbol{L}_{10}$ lives.

3. Based on bearing endurance data, 92 percent of the bearing sets that would be subject to rework would result in $\boldsymbol{L}_{10}$ lives equaling and/or exceeding that predicted for new bearings with the remaining 8 percent having the potential to achieve the analytically predicted life of new bearings when one of the rings is replaced at rework.

4. The potential savings from bearing rework varies from 53 to 82 percent that of new bearings depending on the cost, size and complexity of the bearing.

\section{References}

1. Martin, J.A., and Eberhardt, A.D. (1967), "Identification of Potential Failure Nuclei in Rolling Contact Fatigue," ASME Jour. of Basic Engr., 89, 4, pp. 932-942.

2. Littman, W.E., and Widner, R.L. (1966), "Propagation of Contact Fatigue from Surface and Subsurface Origins," ASME Jour. of Basic Engr., 88, 3, pp. 624-636.

3. Leonard, L., Martin, J.A., and Choman, L. (1969), "Surface and Subsurface Observations of Endurance Tested 6309-Size Bearings,” SKF Report AL69MO25, SKF Industries, King of Prussia, PA, Oct. 1969.

4. Zaretsky, E.V., (1987), "Effects of Surface Removal on Rolling-Element Fatigue," Tribology-Friction, Lubrication and Wear, Fifty Years On, in Proc. IMechE, Vol. II, IMechE 1987-5, pp. 829-838.

5. Zaretsky, E.V., Hendricks, R.C. and Soditus, S.M. (2003), "Effect of Individual Component Life Distribution on Engine Life Prediction," Probabilistic Aspects of Life Prediction, ASTM STP 1450, W. S. Johnson and B. M. Hillberry, Eds., ASTM International, West Conshohocken, PA.

6. Stanley, D.C. (1974), "Bearing Field Inspection and Refurbishing." Paper presented at Symposium on Propulsion System Structural Integration and Engine Integrity, Naval Post Graduate School, Monterey, CA, Sept. 3-6, 1974.

7. Hanau, H. (1976), "Restoration by Grinding of Aircraft Ball and Roller Bearings-A Manufacturer's Viewpoint," Bearing Restoration by Grinding, H. Hanau, et al., eds., USAAVSCOM-TR-76-27, U.S. Army Aviation Systems Command, pp. 1-23.

8. Parker, R.J., Zaretsky, E.V., and Chen, S.M. (1976), "Evaluation of Ball and Roller Bearings Restored by Grinding," Bearing Restoration by Grinding, H. Hanau, et al., eds., USAAVSCOM-TR-76-27, U.S. Army Aviation Systems Command, pp. 24-42.

9. Bull, H.L. (1976), "Bearing Restoration-A Users Viewpoint," Bearing Restoration by Grinding, H. Hanau, et al., eds., USAAVSCOM-TR-76-27, U.S. Army Aviation Systems Command, pp. 59-66.

10. Irwin, A.S., Anderson, W.J., and Derner, W.J. (1985), "Review and Critical Analysis-Rolling-Element Bearings for System Life and Reliability," NASA CR-174710.

11. Zaretsky, E.V. (1997), "Rolling Bearing and Gear Materials," Tribology for Aerospace Applications, E.V. Zaretsky, ed., STLE SP-37, STLE, Park Ridge, IL, pp. 441-442, 757-761.

12. Coy, J.J., Zaretsky, E.V., and Cowgill, G.R. (1977), Fatigue Life Analysis of Restored and Refurbished Bearings," NASA TN D-8486.

13. Lundberg, G., and Palmgren, A. (1947), "Dynamic Capacity of Rolling Bearings," Acta Polytechnica, 1, 3, Stockholm. 
14. Zaretsky, E.V. (1992), STLE Life Factors for Rolling Bearings, STLE SP-34, STLE, Park Ridge, IL, pp. 233298.

15. Weibull, W. (1939), “A Statistical Theory of the Strength of Materials,” Ingeniors Etanskaps AkademienHandlinger, 151.

16. Weibull, W. (1939), “The Phenomenon of Rupture of Solids,” Ingeniors Vetenskaps Akademien, 153.

17. Weibull, W. (1951), “A Statistical Distribution Function of Wide Applicability,” ASME Jour. of Applied Mechanics, 18, 3, pp. 293-297.

18. Lundberg, G., and Palmgren, A. (1952), “Dynamic Capacity of Roller Bearings,” Ingeniors Etanskaps Akademien-Handlinger, 210.

19. Zaretsky, E.V. (1994), "Design for Life, Plan for Death, Machine Design, 66, 15, Aug., 1994, pp. 55-59.

20. Zaretsky, E.V., Poplawski, J.V., and Peters, S.M. (1996), Comparison of Life Theories for Rolling-Element Bearings," Trib. Trans., 39, 2, pp. 237-248, 501-503.

21. Poplawski, J.V., Peters, S.M, and Zaretsky, E.V. (2001), "Effect of Roller Profile on Cylindrical Roller Bearing Life Prediction-Part I: Comparison of Bearing Life Theories," Trib. Trans., 44, 3, pp. 339-350.

22. Poplawski, J.V., Peters, S.M, and Zaretsky, E.V. (2001), "Effect of Roller Profile on Cylindrical Roller Bearing Life Prediction-Part II: Comparison of Roller Profiles,” Trib. Trans., 44, 3, pp. 417-427.

23. Vlcek, B.L., Hendricks, R.C., and Zaretsky, E.V. (2003), "Determination of Rolling-Element Fatigue Life from Computer Generated Bearing Tests," Trib. Trans., 46, 4, pp. 479-493.

24. Harris, T.A. (1995), "Final Report-Establishment of a New Rolling Bearing Contact Life Calculation Method," U.S. Naval Air Warfare Center, Aircraft Division Trenton, Contract No. N68335-93-C-0111.

25. Harris, T.A., and McCool, J.I. (1966), "On Accuracy of Rolling Bearing Fatigue Life Prediction," ASME Jour. of Trib., 118, 2, pp. 297-310.

26. Zaretsky, E.V., Poplawski, J.V., and Miller, C.R. (2001), "Rolling Bearing Life Prediction-Past, Present and Future," in Proc. Int. Trib. Conf.. Nagasaki, 2000, 1, Japanese Society of Tribologist, Tokyo, Japan, pp. 101107. 


\begin{tabular}{|c|c|c|}
\hline \multicolumn{2}{|c|}{ REPORT DOCUMENTATION PAGE } & $\begin{array}{l}\text { Form Approved } \\
\text { OMB No. 0704-0188 }\end{array}$ \\
\hline \multicolumn{3}{|c|}{$\begin{array}{l}\text { Public reporting burden for this collection of information is estimated to average } 1 \text { hour per response, including the time for reviewing instructions, searching existing data sources, } \\
\text { gathering and maintaining the data needed, and completing and reviewing the collection of information. Send comments regarding this burden estimate or any other aspect of this } \\
\text { collection of information, including suggestions for reducing this burden, to Washington Headquarters Services, Directorate for Information Operations and Reports, } 1215 \text { Jefferson } \\
\text { Davis Highway, Suite 1204, Arlington, VA 22202-4302, and to the Office of Management and Budget, Paperwork Reduction Project (0704-0188), Washington, DC 20503. }\end{array}$} \\
\hline 1. AGENCY USE ONLY (Leave blank) & $\begin{array}{r}\text { 2. REPORT DATE } \\
\text { May } 2005\end{array}$ & $\begin{array}{l}\text { D DATES COVERED } \\
\text { echnical Memorandum }\end{array}$ \\
\hline \multicolumn{2}{|c|}{$\begin{array}{l}\text { 4. TITLE AND SUBTITLE } \\
\text { Effect of Rolling Bearing Refurbishment and Restoration on Bearing Life } \\
\text { and Reliability }\end{array}$} & 5. FUNDING NUMBERS \\
\hline \multicolumn{3}{|c|}{ Erwin V. Zaretsky and Emanuel V. Branzai } \\
\hline $\begin{array}{l}\text { 9. SPONSORING/MONITORING AGEN } \\
\text { National Aeronautics and Sp } \\
\text { Washington, DC 20546-00 }\end{array}$ & $\begin{array}{l}\text { NAME(S) AND ADDRESS(ES) } \\
\text { Administration }\end{array}$ & $\begin{array}{l}\text { 10. SPONSORING/MONITORING } \\
\text { AGENCY REPORT NUMBER } \\
\text { NASA TM-2005-212966 }\end{array}$ \\
\hline
\end{tabular}

\section{SUPPLEMENTARY NOTES}

Prepared for the 2004 Annual Meeting and Exhibition sponsored by the Society of Tribologists and Lubrication Engineers, Toronto, Canada, May 17-20, 2004. Erwin V. Zaretsky, NASA Glenn Research Center; and Emanuel V. Branzai, Bearing Inspection, Inc., 4422 Corporate Center Drive, Los Alamitos, California 90720-1570. Responsible person, Erwin V. Zaretsky, organization code RS, 216-433-3241.

12a. DISTRIBUTION/AVAILABILITY STATEMENT 12b. DISTRIBUTION CODE

Unclassified - Unlimited

Subject Categories: 37 and 38

Available electronically at http://gltrs.grc.nasa.gov

This publication is available from the NASA Center for AeroSpace Information, 301-621-0390.

13. ABSTRACT (Maximum 200 words)

For nearly four decades it has been a practice in commercial and military aircraft application that rolling-element bearings removed at maintenance or overhaul be reworked and returned to service. The work presented extends previously reported bearing life analysis to consider the depth $\left(\boldsymbol{Z}_{45}\right)$ to maximum shear stress $\left(\boldsymbol{\tau}_{45}\right)$ on stressed volume removal and the effect of replacing the rolling elements with a new set. A simple algebraic relationship was established to determine the $\boldsymbol{L}_{\mathbf{1 0}}$ life of bearing races subject to bearing rework. Depending on the extent of rework and based upon theoretical analysis, representative life factors $(\boldsymbol{L F})$ for bearings subject to rework ranged from 0.87 to 0.99 the lives of new bearings. Based on bearing endurance data, 92 percent of the bearing sets that would be subject to rework would result in $\boldsymbol{L}_{\mathbf{1 0}}$ lives equaling and/or exceeding that predicted for new bearings with the remaining 8 percent having the potential to achieve the analytically predicted life of new bearings when one of the rings is replaced at rework. The potential savings from bearing rework varies from 53 to 82 percent that of new bearings depending on the cost, size and complexity of the bearing.

\begin{tabular}{|c|c|c|}
\hline \multicolumn{3}{|c|}{ Rolling-element bearings; Bearing rework; Life prediction; Bearing life } \\
\hline $\begin{array}{l}\text { 17. SECURITY CLASSIFICATION } \\
\text { OF REPORT } \\
\text { Unclassified }\end{array}$ & $\begin{array}{l}\text { 18. SECURITY CLASSIFICATION } \\
\text { OF THIS PAGE } \\
\text { Unclassified }\end{array}$ & $\begin{array}{l}\text { 19. SECURITY CLASSIFICATION } \\
\text { OF ABSTRACT } \\
\text { Unclassified }\end{array}$ \\
\hline
\end{tabular}



